\title{
ANVERSO DE UN PARAÍSO
}

Vizania Amezcua*

En busca de aquello que viniera a sorprenderla porque lo ignoraba, la mujer -de pardo atuendo, rostro enjuto y ojos opacos- compró el boleto a Río de Janeiro dejando que la expendedora de la línea aérea - de robusta y aburrida expresión, sofocada por el ajustado traje azul marino que debía portar seis días a la semana- pensara que su deseo de viajar a Brasil obedecía a: el franco desfogue carnavalesco, b: ese pensamiento que en extraña ilusión une calor con paraíso, c: la música, en especial esa canción que recrea en la mente de todos el malecón de Ipanema y el andar de la mítica muchacha, d: caipirinhas recién servidas con hielo, cachaça de 40 grados y jugo-cáscaras de limón, e: horizontes tras el mar para dejar que la mirada se pierda, o: pieles lustrosas y bronceadas para extraviarse en ellas; última idea que la expendedora creyó la razón más acertada -por lo que podía leer en la desolada expresión de la otra-para elegir la nación carioca como destino.

Pero aquella mujer, la otra, no estaba interesada en ninguna de esas razones para emprender el viaje, sino en aquello que había escuchado decir, en franco denuesto, sobre los turistas, y cómo éstos siguen, en una suerte de encantamiento similar al del flautista de Hamelin, las rutas obligadas y nombres señalados en las guías como una forma de enfrentar el extrañamiento y evitar el extravío; los viajeros en cambio -más inspiradores para ella-optaban por depositar su entera confianza

* Narradora. 
en los pasos y en que el azar de perderse los llevara a descubrir otra fisonomía citadina, aquello que no está a la vista de todos, costumbres de las que no habla ningún cronista, sitios que no figuran en mapa alguno, esa posibilidad latente que durante el extravío viniera a sorprenderla porque la ignoraba.

Después del vuelo, entre el azar de los días previstos para la estancia, anónimos ojos vieron cómo su enjuta y fea apariencia, de infatigable caminar, abandonaba las calles de bicolor empedrado y las fachadas de ostentosa arquitectura para perderse en calles de tierra, a la sombra de ruinosas construcciones, internarse en las favelas o arriesgarse a beber cachaça en esos sórdidos expendios que pueblan las afueras de Río y algunas playas poco visitadas. Como los viajeros, aquella mujer había ido encontrando esos instantes de paraíso que esconde la otra ciudad, oculta para siempre a la mirada de los turistas; no obstante, hasta ese momento, nada había que pudiera mencionar en verdad digno de despertarle la sorpresa porque lo ignoraba.

Un día de esos -30 de septiembre, seis antes de la elección en que Luiz Inácio 'Lula' Da Silva fuera elegido presidente de Brasil- aborda un ómnibus del transporte urbano con la franca intención de volver a extraviarse, de no saber a dónde la conducirá el trayecto que se prolonga cuando el ómnibus avanza por una estrecha callejuela e intempestivamente se detiene y seis hombres con rostro de pesadilla lo abordan por ambos extremos. Para aquella mujer la palabra terror aparece entonces debido a: las órdenes iracundas en esa lengua invertebrada que no llegaba a entender, b: ese intenso olor a gasolina que inunda sus pulmones cuando dos de esos hombres rocían - la rocían- junto con los otros pasajeros y todo lo que hay dentro del autobús, c: el chasquido y la flama roja de un primer encendedor, a la que le sigue otra y otra, d: la desgarradura en los gritos y el crujido de lo que arde, e: la certeza de que esto es lo último que llegará a ver porque no puede salir del autobús mientras los otros la empujan, la arrollan, la dejan tirada entre un asiento y el pasillo y, sólo hasta ese momento, como sucede con algunos viajeros, llegan la revelación y la certeza, aquello que en verdad la sorprende porque lo ignoraba, esa porción 
de infierno de la que no está exento paraíso alguno, incluso el que ella había encontrado, y de la que no habló ningún cronista, expuesta como el gusto, en manos de los operantes del narcotráfico brasileño, por intimidar al oponente con lo que podría llamarse una nueva versión de pira funeraria, digna del siglo XXI: la inmisericorde respuesta al encarcelamiento de Fernandinho Beira-Mar-líder rojo-que atropella todo sin importar el paso de los viajeros y sus travesías por la ciudad carioca, la desaparición de una mujer extranjera, su boleto de regreso abandonado en una habitación de hotel. 
La reproducción total o parcial de este artículo se podrá hacer si el ITAM otorga la autorización previamente por escrito. 